\title{
Perception of Cervical Cancer and Cervical Screening, And Uptake of Pap Smear Among Female Employees of the Jos University Teaching Hospital And Its Environs
}

\author{
P.O. Eka ${ }^{1}$, I.O.A Ujah' ${ }^{2}$, V.C Pam ${ }^{2}$, T.Z Swende ${ }^{1}$, P.H Daru ${ }^{2}$, M.Maanongun ${ }^{1}$ \\ ${ }^{I}$ Benue State University Teaching Hospital, Makurdi, North-Central Nigeria \\ ${ }^{2}$ Jos University Teaching Hospital, Jos, North-Central Nigeria
}

\begin{abstract}
Background: Cervical cancer is the most common cancer and leading cause of death from cancer among women in Nigeria owing to late presentation. This is attributed to lack of an effective national cervical cancer screening programme or poor utilization of the few existing services.

Objective: This study was undertaken to determine the perception of female employees of the Jos University Teaching Hospital (JUTH) and those from its immediate environ regarding cervical cancer and Pap smear, their attitude towards Pap smear and their uptake of the available cervical screening service in the hospital.

Methodology: The study was a cross-sectional questionnaire survey of 368 female employees of JUTH and of those in its environ. The predesigned, pretested questionnaire explored the socio-demographic characteristics, awareness of cervical cancer and Pap smear test, attitude to and uptake of Pap smear. The variations of these parameters with socio-demographic determinants were subjected to statistical analysis at a $P$ value of $<0.05$.

Result: Majority of the respondents (58.2\%) belonged to the other ethnic groups as opposed to Igbo, Yoruba and Hausa/Fulani. Majority of them were married (70.7\%). Three hundred and fourteen (85.3\%) had tertiary education. Nurses accounted for $48.4 \%$ of the respondents. Majority of the respondents (89.1\%) were aware of cervical cancer; $87 \%$ were aware of Pap smear; $98.9 \%$ displayed a positive attitude towards Pap smear as a screening test; however, only $32.6 \%$ had ever had a pap smear. Despite this, more than half of them (57.6\%) were aware of the cervical screening service in JUTH. The main determinants of awareness of cervical cancer and Pap smear were age and educational status; while age and marital status were the major determinants of Pap smear uptake, educational level having no significant influence on Pap smear uptake.

Conclusion: Despite the display of high awareness of cervical cancer and Pap smear as a screening test, and apparent good attitude to Pap smear by respondents and the presence of a cervical screening centre within their reach, Pap smear uptake amongst the respondents was poor. There is, therefore, a need for intensive advocacy in favour of a good attitude towards Pap smear and its uptake by the respondents and other women.
\end{abstract}

Keywords: Cervical cancer, Pap smear cytology,perception, Pap smear uptake

\section{Introduction}

Cervical cancer is the most common cancer in the developing world and the leading cause of death from cancer among women in such countries. ${ }^{1}$ Of the estimated annual worldwide 500,000 new cases of cervical cancer, eighty percent occur in the developing world. ${ }^{2}$ Nigeria records 25,000 new cases every year. ${ }^{3,4,6}$ The latest incidence of 25/100,000 in Nigeria is still behind the estimate of about 320/100,000 in the Republic of South Africa.

Although highly preventable, cervical cancer has a high mortality in Nigeria and other developing countries because of the absence of effective screening programmes. Scarce resources, limited infrastructure and competing health priorities have prevented or frustrated most developing countries from implementing successful cervical cancer prevention and control programmes. Since the majority of women present late, existing scarce resources are typically allocated to high-cost treatment of advanced or late-stage disease, which rarely saves women's lives, most of them dying a miserable death. In addition, the HIV epidemic has contributed to the high incidence of cervical cancer in sub-Saharan Africa. ${ }^{8,9,10}$

The value of screening for cervical cancer has been proven. Such programmes in developed nations have achieved a decrease in incidence and mortality by $80 \% .^{11,12,13}$ The high burden of cervical cancer among our sexually active women and the effectiveness of cervical screening in reducing its morbidity and mortality call for the establishment of an organized national screening programme. 
The Jos University Teaching Hospital has established a cervical cancer screening centre for sexually active women within its catchment area and beyond. However, the success of such a programme depends mainly on its acceptance and utilization by the women for whom it is established. This, in turn, depends on their knowledge of cervical cancer, knowledge of the significance of cervical screening and its uptake. ${ }^{14}$

This study was undertaken to assess what the average female employee in our centre knew about cervical cancer; what they knew and felt about cervical screening and their utilization of the available cervical screening service. Since the service is within their reach, their knowledge of cervical cancer and Pap smear test and their attitude to and utilization of the service may probably impact positively on their ability and desire to act as vanguards of the campaign for the acceptance and uptake of cervical screening by other women outside the hospital setting. The fact that the study population comprised women from diverse socio-economic backgrounds will further drive home this point. ${ }^{2}$

\section{Materials And Methods}

This cross-sectional study was conducted by means of a predesigned, pre-tested questionnaire at the Jos University TeachingHospital(JUTH) and its environs located in Jos, the capital city of Plateau State, NorthCentral Nigeria.

The minimum sample size was calculated using the formula by Kish ${ }^{15,16}: \mathrm{N}=\mathrm{z}^{2} \mathrm{pq} / \mathrm{d}^{2}$, where $\mathrm{p}$ was the awareness of $50 \%(0.5)^{11}$ in a similar study among rural and urban womenin South Africa, $\mathrm{z}=1.96, \mathrm{q}=(1-$ $\mathrm{p})=0.5$ and $\mathrm{d}=0.05$. Therefore, $\mathrm{N}$ (theminimum sample size) was 384 . A sample size of 400 was selected to enhance the power of the study.

Subjects were selected by systematic random sampling technique from every department in the hospital and everyhousehold (already preselected by simple random sampling) in its neighbouring environ. The first respondents were selected by balloting and thereafter every fifth consenting respondent was recruited into the study. The questionnaire was designed to elicit basic socio-demographic characteristics, knowledge of cervical cancer, and knowledge of screening with Papanicolaou's smear and the attitude to and extent of utilization of Pap smear.

The questionnaires were retrieved and appropriately completed ones were entered into SSPS(version 17) software. Frequency tables were generated. Factors such as age, marital status and educational status were studied to find out the possible determinants of knowledge of cervical cancer, knowledge of Pap smear and utilization of Pap smear among the respondents. Observed differences were subjected to Chi-square test and the level of statistical significance set at $\mathrm{P}<0.05$. Ethical approval was obtained for the study.

\section{Results}

Three hundred and sixty-eight (368) appropriately completed questionnaires, out of the four hundred administered and retrieved, were analyzed (i.e. $92 \%$ retrieval rate).

The Table shows the sociodemographic characteristics of the respondents. Majority of them (72.3\%) belonged to the age group $30-59 ; 70.7 \%$ were married and $76.1 \%$ were parous. Three hundred and fourteen $(85.3 \%)$ of the respondents had tertiary education; thirty-six $(9.8 \%)$ had secondary education; twelve(3.3\%) had primary education while six $(1.6 \%)$ had no formal education. Fifty-eight point two percent $(58.2 \%)$ of them belonged to other ethnic groups, while Hausa/Fulani, Igbo and Yoruba accounted for 12.5\%, 13.0\% and 16.3\% of respondents respectively. Nurses accounted for $48.4 \%$ of the respondents.

\section{Knowledge Of Cervical Cancer And Pap Smear}

Three hundred and twenty-eight $(89.1 \%)$ had heard of cervical cancer while $73.9 \%$ knew it was associated with abnormal vaginal bleeding. Nine point eight percent $(9.8 \%)$ of them could not list any risk factors or symptoms of cervical cancer. Three hundred and six (83.2\%) believed it was preventable; while two hundred and twelve of them (57.6\%) knew about the existence of a cervical screening centre in JUTH. Three hundred and twenty (87.0\%) respondents had heard of Pap smear, while two hundred and ninety-eight (81.0\%) agreed it was for the prevention of cervical cancer.

\section{Attitude And Utilization Of Pap Smear}

Three hundred and twenty-six $(88.6 \%)$ respondents felt that cervical cancer posed a serious problem in Nigeria while $98.9 \%$ of them would recommend or have regular Pap smear if the service was available or affordable. Only one hundred and twenty $(32.6 \%$ ) had had a previous pap smear while the remaining $67.4 \%$ had never done so. Of the two hundred and forty-eight $(67.4 \%)$ who had never had a pap smear, $58.1 \%$ of them said they had never given a thought to having a pap smear; $25 \%$ said they had never seen themselves as being at risk of having a cervical cancer; $15.3 \%$ said service was not available; a mere $1.6 \%$ of them said they could not afford the service. 
Sixty-four point seven percent $(64.7 \%)$ of the respondents aged 30 years and above were aware of cervical cancer compared to $24.5 \%$ of the younger respondents $\left(X^{2}=76.1401 ; p<0.0001\right)$. Pap smear awareness was found in $59.8 \%$ of those 30 years and above, while it was found in only $21.2 \%$ of those below 30 years $\left(X^{2}=52.3490 ; p<0.0383\right)$. Pap smear uptake was $31.0 \%$ in the former and $1.6 \%$ in the latter respectively $\left(X^{2}=56.7242 ; \mathrm{p}<0.0153\right)$. Significantly higher proportion of women with secondary education and above $(87.5 \%)$ were aware of cervical cancer compared with only $1.6 \%$ of those with primary education and below $\left(\mathrm{X}^{2}=43.6711 ; \mathrm{p}<0.0000\right)$. Similarly, $79.4 \%$ of the former compared to $1.6 \%$ of the latter had knowledge of Pap smear $\left(X^{2}=27.311 ; \mathrm{p}<0.0000\right)$.

There was no statistically significant difference in the uptake of Pap smear between the two groups based on differences in educational status $\left(X^{2}=3.4486 ; \mathrm{p}<0.3275\right)$.

There was no significant difference between those who were currently or previously married (i.e. those who were married, divorced or widowed) and the single ones with regard to the awareness of cervical cancer and that of Pap smear. $\left(X^{2}=4.1982 ; \mathrm{p}<0.2408\right.$ and $\mathrm{X}^{2}=0.8600 ; \mathrm{p}<0.8351$ respectively). However, significantly higher proportion of those who were currently or previously married $(31.5 \%)$ incomparison to the single women $(1.1 \%)$ had had a previous pap smear $\left(\mathrm{X}^{2}=23.8547 ; \mathrm{p}<0.0000\right)$.

Table: sociodemographic characteristics of the respondents

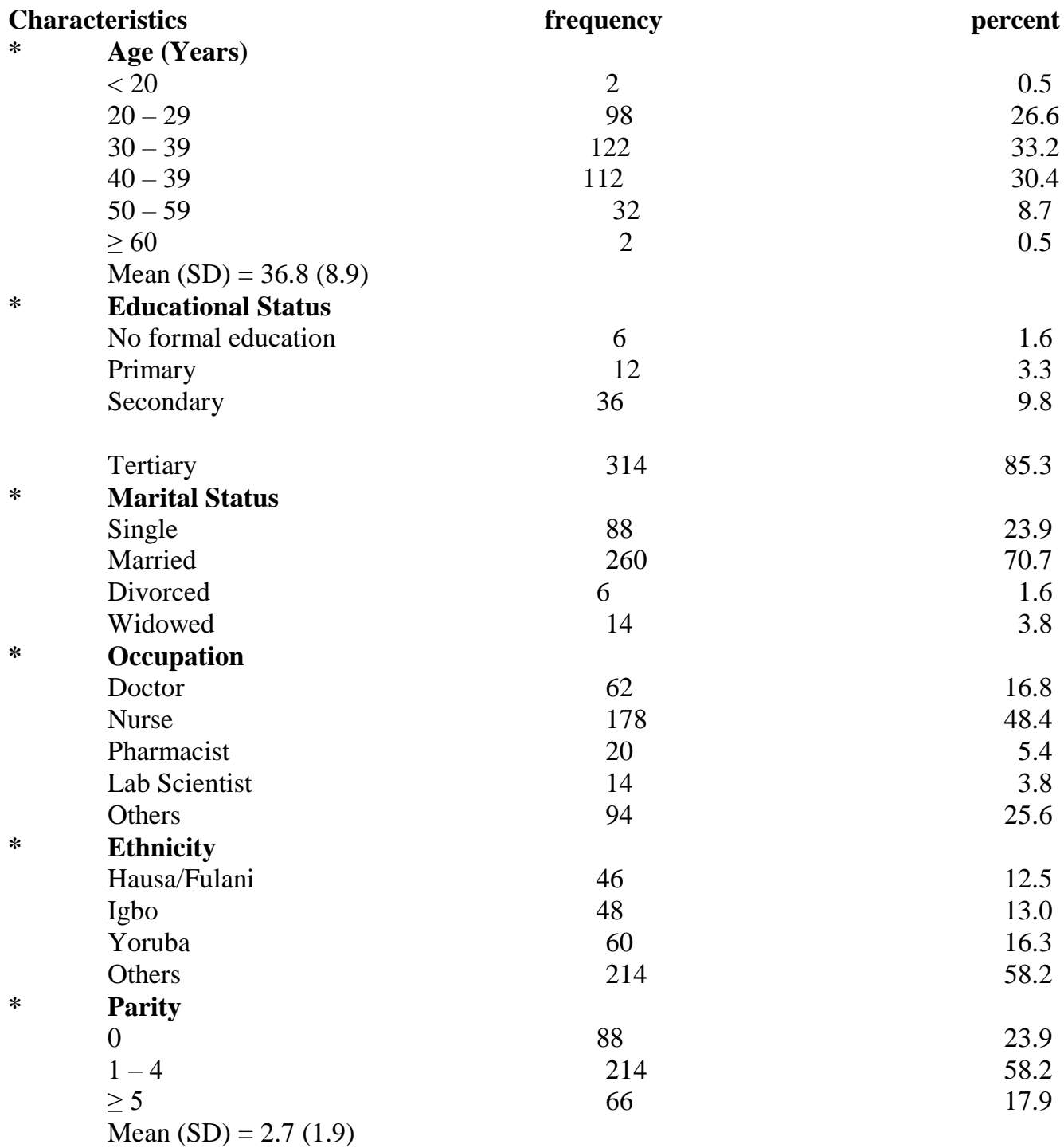

\section{Discussion}

The results of the study show that female employees of our centre have high knowledge of cervical cancer, Pap smear test, and good attitude towards Pap smear but had poor utilization of the available cervical screening centre in JUTH. Almost $90 \%(89.1 \%)$ of the respondents had heard of cervical cancer. This was 
similar to an awareness of $91.7 \%$ reported in a survey of 144 female health professionals in Umuahia and Port Harcourt. ${ }^{17}$ Eighty-one percent $(81.0 \%)$ of them believed that cervical screening was used for preventing cervical cancer. This was in agreement with a recent survey of 166 female health professionals, in hospitals in Abuja, who displayed high awareness (72.9\%) of the importance of cervical screening. ${ }^{18}$ The high awareness of cervical cancer, Pap smear and importance of Pap smear exhibited by the respondents was not unconnected with the high population of female health professionals among them.

Although more than half of the respondents (57.6\%) were aware of the presence of the cervical screening service in our centre, only $32.6 \%$ had had a Pap smear. Majority of those who never had a Pap smear explained that they either did not give a thought to having a Pap smear test $(58.1 \%)$ or they never saw themselves as being at risk of developing cervical cancer (25.0\%), while only $15.3 \%$ gave non-availability as the main reason for not having a Pap smear. The first two reasons imply the poor perception or appreciation of the risk of cervical cancer and the value of Pap smear in the prevention and control of cervical cancer.

In this study, age was a positive correlate of the knowledge of cervical cancer, Pap smear and its uptake. The respondents 30 years and above were highly well informed about cervical cancer and Pap smear and were more likely to present themselves for cervical screening. A series from Australia quoted similar findings with regard to age and marital status. ${ }^{19}$ In this study, marital status did not seem to have any significant influence on the knowledge of the disease and Pap smear. The fact that majority of the respondents $(76.1 \%)$ were either currently or previously married might have nullified marital status as a confounding determinant of the awareness of cervical cancer and Pap smear in this study. However, like the Australian study, marital status had a positive impact on the uptake of cervical screening among the respondents.

High educational attainment (secondary school and above) was associated with a higher awareness of cervical cancer and cervical screening but had no significant influence on the utilization of cervical screening test. This was in disagreement with the study by Skaer et al in which higher levels of education was associated with higher utilization of Pap smear. ${ }^{20}$

In conclusion, the study shows that high awareness of cervical cancer and Pap smear and provisions of a cervical screening service are not sufficient to ensure successful uptake or utilization by women within the radius the service is located.

There is, therefore, a need for a more intensive campaign to sensitize the public to the existing threat of cervical cancer and to the benefits and value of screening as a preventive measure and for detection and treatment of premalignant disease.

The Federal Ministry of Health should partner with NGOs, the Federal Government and other stakeholders interested in promoting women's health to provide and administer the approved HPV vaccines against genital warts and cervical cancer. ${ }^{21}$

The average female employee of all health institutions, regardless of their socioeconomic class or occupation, should be armed with enough information about cervical cancer and Pap smear, so that they may develop the right attitude towards Pap smear and its uptake. This, in turn, will help them to act as vanguards for the campaign against cervical cancer and for the uptake of Pap smear by women in our communities.

Apart from limitations due to sampling and systematic error from information bias, one major limitation was the tacit reluctance of some of the female employees, especially the non-health workers, and other women from the neighbouring environ to participate in the study. This led to a bias in favour of higher recruitment of professional health workers (nurses, doctors, etc).

\section{References}

[1]. Parkin D.M, Laara E, Muir C.S. Estimates of the worldwide frequency of sixteen major cancers in 1980. Int J Cancer, 1988; 41(2): 184-197.

[2]. Parkin D.M, Pisani P, Ferlay J. Estimates of worldwide incidence of 18 major cancers in 1985. Int J Cancer, 1993; 54:594-606.

[3]. Solanke T.F. Cancer in Nigeria. Nigerian Medical Association (OyoState) Annual Guest Lecture, 1996

[4]. Ayinde O.A, Ogunbode O.O, Adebayo O.J. Determinants of cervical cancer knowledge and the utilization of screening among a Nigerian female population. Trop J Obstet Gynaecol, 2005; 22(1): 21-24.

[5]. Edozien L.C, Adewole I.F. Cervical cancer in Nigeria - A need for early detection. Afr. J Med Sci, 1993; 22:87-92.

[6]. Babarinsa I.A, Akang E.E.U and Adewole I.F. Pattern of gynaecological malignancies at the Ibadan cancer registry (1976-1995). Nig. Qt. J. Med, 1998; 8:103-106.

[7]. Cronje H.S, Cooreman B.F, Niemand T, et al. Alternative methods of screening for cervical neoplasia. In: Chanen W and Atkinson K (Eds). 9th World Congress of cervical pathology and colposcopy. Monduzzi Editore: Sydney Australia, 1996:499-503.

[8]. JSTOR: Reproduction Health Matters: Women's Health Policies: Organizing for change, 1995; 3(6): 60 -71 (Assessed on 15/08/07). E-medicine.

[9]. University College London hospitals (UCL) Elizabeth Garrett Anderson: Institute for Women's Health Project for Cervical Screening in Nigeria. (Assessed on 15/08/07). E-medicine.

[10]. Sha S, Montgomery H, Smith C, et al. Cervical Screening in HIV positive women: characteristics of those who default and attitudes towards screening. HIV Medicine, 2006; 7(1):46-52.

[11]. Wellensiek N, Moodley M, Moodley J, Nkwanyana N. Knowledge of cervical cancer screening and use of cervical screening facilities among women from various socioeconomic backgrounds in Durban, Kwazulu Natal, South Africa. Int J Gynecol Cancer, 2002; 12(4):376-382. 
[12]. Phillips Z, Avis M, Whynes D.K. Knowledge of cervical cancer and screening among women in east-central England. Int J Gynecol Cancer, 2005; 15(4); 639-645.

[13]. Gichangi P, Estambale B, Bwayo J, Rogo K, et al. Knowledge and practice about cervical cancer and Pap smear testing among patients at Kenyatta National Hospital, Nairobi, Kenya. Int J Gynecol Cancer, 2003; 13(6):827-833.

[14]. Conway K. Attitude to Papanicolaou’s smears. J Psychomatic Obstet Gynaecol, 1996; 17:189-194.

[15]. Kish L. Survey sampling. John Wiley and sons, New York. 1965: 19-20

[16]. Araoye M.O. Subjects selection. In: Araoye M.O (Ed). Research Methodology with Statistics for Health and Social Sciences. $1^{\text {st }}$ ed. Nathadex Publishers. 2003:115-129.

[17]. Anya S.E, Oshi D.C, Nwosu S.O, Anya A.E. Knowledge, Attitude and Practice of female health professionals regarding cervical cancer and Pap smear. NJM, 2005; 14(3):283-286.

[18]. Olaniyan O.B, Agboghoroma O.C, Ladipo O.P. Knowledge and Practice of Cervical Screening among female health workers in hospitals in Abuja Metropolis, Nigeria. Trop J Obstet Gynaecol, 2000; 17:18-20.

[19]. Siahpush M, Singh G.K. Sociodemographic predictors of Pap test receipt, currency and knowledge among Australian women. Prev. Med, 2002; 35(4):362-368.

[20]. Skaer T.L, Robison L.M, Sclar D.A, Harding G.H. Cancer screening determinants among Hispanic women using migrant health clinics. J Health Care Poor Underserved, 1996; 7(4):338-354.

[21]. US Food and Drug Administration. FDA Licenses new vaccine for Prevention of Cervical Cancer and other Diseases in Females caused by Human Papillomavirus. Rockville, MD. National Press Office; June 8, 2006: 06-77. 